BIORHEOLOGY $19 ; 231-235,1982$

0006-355X/82/010231-05\$03.00/0 Printed in the USA.

Copyright (c) 1982 Pergamon Press Ltd. All rights reserved.

\title{
SECOND EUROPEAN CONFERENCE ON CLINICAL HEMORHEOLOGY
}

THE HISTORY OF RHEOLOGY

George W. Scott Blair

Grist Cottage, Iffley, Oxford, England

(Accepted by Editor-in-Chief A.L. Copley)

T am extremely grateful for the generosity and kindness of this organization, inviting me to give this talk here today on the History of Rheology, not up to date but a history up to a fairly recent time. There is just one very early rheological thing that I should like to speak about and it was found by a German Egyptologist (in, I think, 1964 when he published his paper). He was in Egypt and he found they used a 'water clock'. Now, the water clock consisted of a cone with a little hole in the bottom. It was filled with water at night and the water ran down through the hole and the angle of the cone was, of course, very critical to get a linear relation between the scale and time. When this particular water clock was reconstructed, it was not very badly damaged, it must have been used 1500 or 1600 B.C. So it was a very old clock, but, when it was reconstructed, the German investigator found that the angle was not quite right. It was a few degrees out and it seemed so unlikely that an Egyptian physicist of that date (Egyptians were very good scientists) should have made a mistake. So the Egyptologist looked around to see what was the cause of this discrepancy in the angle of the cone. He found that at night, in Egypt apparently at the beginning of the night, the temperature is very high and the waterhas, of course, low viscosity. As night goes on, the temperature falls very dramatically and is quite low in the morning and the viscosity of the water rises. So this subtle Egyptian rheologist, if we may call him that, adjusted the angle of the cone to correct for the change in viscosity with the night. A truly remarkable thing to have happened in the 15 th or 16 th Century B.C.

From then on very little real rheology that I can trace has been done. There was a certain amount done in India, i.e., the elasticity of bow strings and things of that kind. Many people during the Middle Ages did experiments, which we should now refer to rather as hydrodynamics than rheology (including Leonardo da Vinci). But, I think, we had better skip all that and come on to the real foundations of rheology as a science, which of course, 
started, I suppose really essentially, with Newton and Hooke. Isaac Newton studied the flow of fluids, by which one means, of course, gases and liquids in relation to pressure. He established the rule that, under certain conditions, with many fluids the rate of flow is proportional to the pressure. We know that with many liquids this is indeed the case and they are still known to rheologists as Newtonian liquids. Hooke was a rather difficult gentleman. He and Newton had a lot of rows; I think, they did not get on well together. Hooke hung strips of various materials from the ceiling of his room in Oxford almost to the ground and loaded these strings with various weights and then measured the extension of the strips for the different weights. He found that with many materials they showed what we now call "perfect elasticity", that is to say that the extension is proportional to the stress or, as Hooke put it so nicely in his day in Latin, 'ut tensio sic vis'. So we still talk about Hookean solids, for solids which are strictly elastic.

Now comes a fairly long gap, I must not take too long with the intervening things that happened, but perhaps one of the next cases, that one should mention, is the first case where, I think, a medical man took a keen interest in rheology and that was Poiseuille in Paris, a French physician. He was clearly interested in the flow of blood through blood vessels. He realized really very sensibly, ( 1830 we are talking about now), that blood vessels are not simple elastic tubes of constant diameter, nor is blood a true fluid in a Newtonian sense. What he did (he must have had plenty of funds), was to get made, specially for him, a number of tubes, glass tubes very carefully constructed to be of even bore all the way down and of different lengths, of course. Then he took various sample liquids and caused them to flow through these tubes. He established a law which, at the time, was regarded as rather surprising, because he found that the rate of flow depended on the inverse of the length, of course, but also on the fourth power of the radius. Now, at that time, the few rheologists who had made a study of these things were convinced, it was the square but Poiseuille said "no, it is the fourth power". Unfortunately, Poiseuille made a mistake, which other scientists have often made. He waited a very long time before publishing his results. In the meantime, a German rheologist by the name of Hagen, not I think knowing of Poiseuille's work at all, repeated the experiment on a much smaller scale with not nearly so many samples, and not such a big experiment, but he found the same law, the same equation. Since he published before Poiseuille got his publication into print, I suppose, according to strict rules, we should call this the Hagen-Poiseuille Law, rather than Poiseuille Law, which it commonly is called because Poiseuille's work was much more intensive and there was far more of it. However, that is the law of flow of a simple liquid. Then, after that, there was a fairly long gap, a good deal of rheology was done, but, I think, we must make a break now. I have not very long; I must go right up to what happened after the First World War.

I must go next to the official acceptance of the word 'rheology'. I was privileged to be Chairman of a meeting, held in Washington, USA, 52 years ago in December 1929. Why they elected such a young man as myself as Chairman of this rather important meeting, I do not know (I was only 27 years old), except possibly because there were very few rheologists in the world at that time and most 
of these who were rheologists were in America, in the eastern states of America. Washington was a good place to hold an Inaugural Meeting and $I$ was put in the chair. They had quite a number of people there from various countries and we accepted formally and officially the name 'Rheology' for 'the Science of the Flow and Deformation of Matter', which, as my old friend the late Markus Reiner pointed out, was not a very good definition because 'Rheo' in the Greek is flow, and elastic deformations are not included in the word Rheology and yet, of course, Rheology certainly includes elastic deformation. However, Rheology was accepted as the official name of the science.

The 'Journal of Rheology' was started which was, I am afraid, short-lived. A society of rheology was started which was intended to be international, but for various reasons did not become international. It was the beginning of what is now the (American) Society of Rheology, I think the largest society of rheology in the world. We also did quite a number of other things at that meeting to set the science of rheology going.

When I came back to England, I had been asked by Eugene C. Bingham, who was one of the founders of rheology (he was Professor of Chemistry at Lafayette College in Easton, Pennsylvania) if I would start a British branch of the Society of Rheology. For certain reasons ( $I$ have not time to go into) I was not able to do this and I do not think that anybody else, in any other country, started branches of the Society of Rheology. Right up until the Second World War and during the war, unknown to us and unknown to our friends from the Netherlands, we in Britain felt that we must have a group of people studying rheology for war purposes in all the various industries. A meeting was held in Reading under the chairmanship of Sir Geoffrey Taylor, at which people from various industries concerned with flow and deformation of materials met and a group was started. We felt, in wartime, it would be rather pompous to call it the 'British Society of Rheology', but we made rather a mistake there. I think, we called it the 'British Rheology Club'. Now, a club in England is a place where people meet and sit and have coffee, smoke cigars and that kind of thing. We had no centre, no geographical centre and we should not have called it a club.

As soon as the war was over, we corrected this and it became and now is the 'British Society of Rheology' and I think it is a very active and potent society. There are several hundred members. It is quite a big society. Meanwhile, of course, in other countries other societies were being formed. In Holland, at the time we were forming our group during the war, our friends (quite unknown to us and, of course, we could not know what was going on there some of the time) were limited in the kind of physics they were allowed to do. They started doing rheology almost as a hobby and formed a group which later became the Dutch Society of Rheology. Then, after the war, the United Nations' UNESCO made an enquiry as to whether rheology, growing very fast at that time in many countries, was sufficiently important a science to have its own International Union like the International Unions of Chemistry and Physics, Biology, and so on, or, if not, whether it could be affiliated to one of the existing Unions and, if so, to which one. So, an International Committee was set up and two people from each 
branch of science were appointed for this committee and I found myself paired off with the late Jan Burgers, who was Professor of Aero- and Hydro-Dynamics in Delft and a really delightful person. He and I became great friends. We had a meeting with all the delegates together here in London at the Royal Society to decide these questions, put to us by UNESCO. The decision was very quickly taken that there was not enough rheology to make a separate union; nor could we agree on any one to which we could affiliate because people, doing rheology, came from so very many different disciplines, that it would have been quite invidious to say that it must be part of Chemistry or part of Physics or part of Biology or whatever it might be. However, we had other things to do and Burgers and I were given a job of looking up all the technical words we could find in the English language (Burger's English was extrememly good), to do with rheology and to give them precise definitions with mathematical formulae if necessary. We did this work together over some years, meeting sometimes in Holland and sometimes in England.

I was working in Reading at the time. He came to Reading and I went to Delft and we did this together. At the end of the time, we produced a document, which was officially accepted by UNESCO, giving a list of Rheological Terms in the English language with their definitions, of course. This is now a very old story, because since then many people have drawn up lists of rheological terms in various languages and given definitions.

In France for example, the "Groupe Français de Rheologie" has produced a very good list of French technical terms and English equivalent terms with full definitions. When $T$ was in Tsrael some years ago ( I do not think we completed this work partly perhaps because of the rather tragic death of the wife of my friend Markus Reiner, Dr. Rivka Reiner, who was Russian born), we actually tried to make a vocabulary in English, French, German, Russian and Hebrew. This would have been quite a big task, but, I think, that was not completed. Anyhow I left Israel after that. I did not see it completed. Meanwhile, rheology was going ahead very fast in this country. The Society of Rheology was growing and then it was felt that there should be International Congresses.

The First International Congress was held not very long after the war (I think, with great courage), by our Dutch friends because Holland was recovering from war conditions which were very difficult. We had this Congress in 1948 at Scheveningen, Holland. We did not have all rheological countries represented, as we did in later Congresses, but it was a very good first Congress and my friend Jan Burgers, (alas, he is no longer with us as he died quite recently, he was an old man), had a great deal to do with organiring this Congress. Then, the second Congress was held in Oxford and it was my job to be secretary of that Congress. After that, International Congresses have been held in various parts of the world every five and now four years. There is an International Committee of Rheological societies throughout the world now, because so many countries now have Societies of Rheology. In fact, any country where rheology is done, has, as far as I know, now a society and there is an International Committee that meets to discuss plans for making arrangements for Congresses in new cities and new parts of the world. 
I had the honor recently of being appointed an Honorary Member of that Committee, although, I am afraid now with my old age and failing sight, I am not able to attend the meetings, but they do plan future Congresses. The last one that $I$ was at was in Lyon, France in 1972 and that brings me to my last point, because I think I have talked almost long enough.

The last point is that Rheology had a daughter. The daughter of Rheology is Biorheology. That is the section of Rheology dealing with biological systems. This became a separate organization with separate International Congresses and an International Journal. Professor Copley and I were co-Editors-in-Chief for 17 or 18 years of the journal BIORHEOLOGY. Now, of course, we come to the final state, the grand-daughter, if you like, of the original Rheology, that is the daughter of Biorheology, became Haemorheology, the study of blood and the vascular system, which we are here to talk about today.

We11, I hope that in this brief and, I am afraid, rather scattered talk, I cannot see - I just have to do it from memory, I have been able to give you some idea of how Rheology came into its present historical condition and to say how grateful I am for the honor that has been done to my wife and myself in inviting me here as guests of the Conference, and also the enthusiasm and interest that is now shown in the application of Rheology to Medicine. I think, it was one of the well known Greek philosophers who said, "Vain is the word of the Philosopher unless it is used to improve the lot of man" and I think that this is one of the things that Rheology is now used to help the medical profession. 